\title{
New insights into cholangiocarcinoma: multiple stems and related cell lineages of origin
}

\author{
Maria Consiglia Bragazzi, Lorenzo Ridola, Samira Safarikia, Sabina Di Matteo, Daniele Costantini, \\ Lorenzo Nevi, Vincenzo Cardinale
}

Sapienza University of Rome, Rome, Italy

\section{Abstract}

\begin{abstract}
Cholangiocarcinoma (CCA) is a heterogeneous group of malignancies that may develop at any level of the biliary tree. CCA is currently classified into intrahepatic (iCCA), perihilar (pCCA) and distal (dCCA) on the basis of its anatomical location. Notably, although these three CCA subtypes have common features, they also have important inter- and intra-tumor differences that can affect their pathogenesis and outcome. A unique feature of CCA is that it manifests in the hepatic parenchyma or large intrahepatic and extrahepatic bile ducts, furnished by two distinct stem cell niches: the canals of Hering and the peribiliary glands, respectively. The complexity of CCA pathogenesis highlights the need for a multidisciplinary, translational, and systemic approach to this malignancy. This review focuses on advances in the knowledge of CCA histomorphology, risk factors, molecular pathogenesis, and subsets of CCA.
\end{abstract}

Keywords Cholangiocarcinoma, classifications, inflammation, cells of origin, stem cells, molecular profiling

Ann Gastroenterol 2018; 31 (1): 1-14

\section{Introduction}

CCA is a heterogeneous group of malignancies emerging at any level of the biliary tree [1-3] (Fig. 1). CCA is classified into intrahepatic (iCCA), perihilar (pCCA) and distal (dCCA) based on its anatomical location [1-3]. Notably, although these three CCA subtypes have common features, they also have important inter- and intra-tumor differences that can affect the pathogenesis and outcome [4-9]. The complexity of the pathogenesis and the pronounced heterogeneity of CCAs have impeded clinical goals in their management [10].

This review focuses on advances in the knowledge of CCA classifications and histomorphology, risk factors, and molecular pathogenesis, as well as the multiple subtypes of CCA. The

Department of Medico-Surgical Sciences and Biotechnologies, Sapienza University of Rome, Rome, Italy

\section{Conflict of Interest: None}

Correspondence to: Vincenzo Cardinale MD, PhD, University Sapienza of Rome, Department of Medico-Surgical Sciences and Biotechnologies, Viale dell'Università 37, 00185 Rome, Italy,

e-mail: vincenzo.cardinale@uniroma1.it

Received 12 June 2017; accepted 14 September 2017; published online 2 November 2017

The study was supported by a sponsored research agreement from Vesta Therapeutics (Bethesda, MD)

DOI: https://doi.org/10.20524/aog.2017.0209 existence of multiple cells of origin is presented and discussed as a possible major determinant of the intertumoral heterogeneity of CCA, suggesting the possibility of a CCA classification based on cells of origin. Finally, a model of interaction between the cell of origin, the molecular alterations, and the underlying liver and biliary pathologies in different CCA subsets is proposed.

\section{New insights into CCA classifications}

In the last few years, a huge number of different classifications have been proposed [1-11]. Currently, CCA is classified as iCCA, pCCA or dCCA [1-3]. However, this classification is biased by some pitfalls. Firstly, CCA is frequently diagnosed at an advanced stage; this is especially true for pCCA, where distinguishing between an intra-hepatic or extra-hepatic location proves challenging [11]. Secondly, small bile ducts and ductules are also present in the perihilar liver parenchyma. Therefore, pCCA may originate either from these smaller ducts or from hilar ducts, though this cannot be discriminated based on gross morphology. Likewise, iCCA may originate from large or small ducts of the intrahepatic biliary tree. Thirdly, recent studies demonstrated that, from a pathological and molecular point of view, there are no differences between pCCA and iCCA that originate from large bile ducts; therefore, the distinction between these two forms of CCA is losing relevance [4,9,12-14]. Taking into consideration the macroscopic pattern of growth, iCCA has been classified as mass-forming (MF), periductal 
infiltrating (PI), and intraductal growing (IG) [2,15]. As far as pCCA and ICCA are concerned, both PI and IG patterns have been recognized. For pCCA a nodular+PI growth pattern predominates (>80\%) [2,5,16-18].

Histologically, the vast majority of pCCAs and dCCAs are mucinous adenocarcinomas. In contrast, iCCAs are highly heterogeneous tumors and several classifications have been proposed $[4,5,9,19]$. The small bile duct type (mixed) iCCAs display an almost exclusively MF growth pattern $[4,5,9,19]$, and are frequently associated with chronic liver diseases (viral hepatitis or cirrhosis) $[4,5,9,19,20]$. Notably, this subtype shares clinicopathological similarities with cytokeratin (CK) 19-positive hepatocarcinoma (HCC) [4,21]. On the other hand, large bile duct type (mucinous) iCCAs may grossly appear as MF, PI or IG types; they are more frequently associated with primary sclerosing cholangitis (PSC) and can be preceded by preneoplastic lesions, such as biliary intraepithelial neoplasm or intraductal papillary neoplasm $[4,5,9,19]$. Interestingly, the large bile duct type (mucinous) iCCAs share phenotypic traits with pCCA and pancreatic cancers [4]. In our opinion, this histological subtyping should be taken into serious consideration because it results in different risk factors, molecular profiles, and clinical management $[3,4,9,14,22-28,52]$.

\section{Multiple risk factors reveal CCA subtype-specific pathogenesis}

The epidemiological profile of CCA and its subtypes (Fig. 1) displays enormous geographic differences. Although in most countries CCA is a rare cancer (incidence $<6 / 100,000$ ), its incidence may reach extremely high peaks in some populations of Chile, Bolivia, South Korea and North Thailand [29]. In particular, the variation in incidence rates is correlated with the different prevalence of risk factors. In regions of Thailand, for example, it is closely related to the incidence of liver flukes [30-32]. In the past century, a progressive increase in iCCA incidence was registered, whereas the incidences of both pCCA and dCCA seem to be decreasing [29]. Fig. 1 summarizes the worldwide epidemiology and incidence trends of intrahepatic and extrahepatic CCA.

In order to review the literature on risk factors associated with iCCA and/or p/dCCA, we searched for case series of iCCA

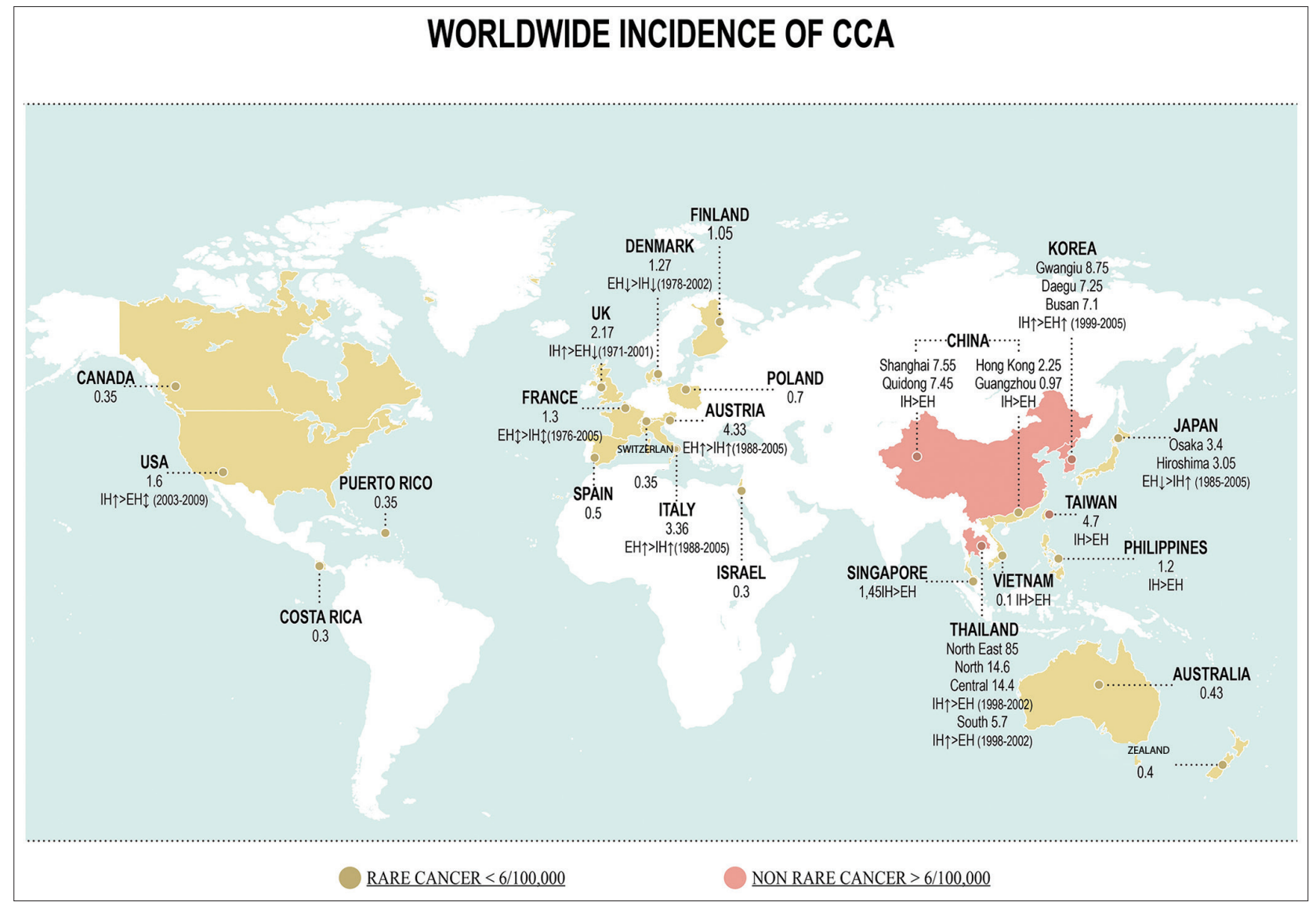

Figure 1 Worldwide incidence (cases/100,000) of cholangiocarcinoma (CCA).

Data refer to the period 1971-2009. Green color identifies areas with lower incidence $(<6 / 100,000$ cases, rare cancer), while pink color indicates countries where CCA is not a rare cancer ( $>6 / 100,000$ cases). Diagnoses have been classified according to the International Classification of Diseases (ICD-O-1, ICD-O-2, ICD-O-3, ICD-10, ICD-V9, ICD-V10, ICD-O). Where available, the more incident form (intrahepatic [IH] vs. extrahepatic $[\mathrm{EH}] \mathrm{CCA}$ ) and the temporal trend of incidence ( $\uparrow$ increasing trend; $\uparrow$ stable trend; $\downarrow$ decreasing trend) have been reported Modified from Banales et al. Nat Rev Gastroenterol Hepatol [ref. 3] 
and p/dCCA diagnosed according to the currently recognized criteria (i.e. European RARECARE) [33], or case series with appropriate topographic classification of histologically verified CCA. The results of these studies, mostly case-control studies, are summarized in Table 1 [34-46].

\section{Methods for collection of case-control studies investigating risk factors and for the preparation of Table 1}

Table 1 was prepared to summarize findings regarding case-control studies that investigated risk factors associated

Table 1 Summary of risk factors significantly associated with iCCA* and/or pCCA/dCCA\# as assessed by case-control studies (Odds ratios by multivariate analyses; all odds ratios reported are significant for the $95 \% \mathrm{CIs}$ )

\begin{tabular}{|c|c|c|c|}
\hline $\begin{array}{l}\text { Risk factors for iCCA } \\
\text { [references] }\end{array}$ & $\begin{array}{l}\text { Odds ratios for } \\
\text { increased risk }\end{array}$ & $\begin{array}{l}\text { Risk factors for pCCA/dCCA } \\
\text { [references] }\end{array}$ & $\begin{array}{l}\text { Odds ratios for } \\
\text { increased risk }\end{array}$ \\
\hline Bile duct diseases and conditions & & Bile duct diseases and conditions & \\
\hline Cholecystitis [36] & 8.5 & Cholecystitis [36] & 5.9 \\
\hline Cholelithiasis $[35,40,161]$ & $10.23-13.5$ & Cholelithiasis $[35,36,45]$ & $2.6-11$ \\
\hline Hepatolithiasis $[77 \S, 37,39,40,43]$ & $50.0-4.8 ; 6.7 \S$ & Hepatolithiasis [45] & 3.09 \\
\hline Choledochal cysts $[36,37,44,59]$ & $10.7-43.03$ & Choledochal cysts [36] & 47.1 \\
\hline Choledocholithiasis $[35,43,161]$ & $4.17-33.35$ & Choledocholithiasis $[36,45]$ & $34,9.84$ \\
\hline Cholangitis/PSC $[36,44]$ & $64.2-75.23$ & Cholangitis/PSC [36] & 45.7 \\
\hline Biliary cirrhosis/PBC $[36,44]$ & $17.08-19.8$ & Biliary cirrhosis/PBC [36] & 11.8 \\
\hline Cholecystectomy $[36,39]$ & $3.6-5.4$ & Cholecystectomy $[35,36,45]$ & $5.8-12$ \\
\hline Digestive diseases & & Digestive diseases & \\
\hline Inflammatory bowel diseases $[36,58]$ & $1.72-3.95$ & Inflammatory bowel diseases $[36,58]$ & $1.1-1.97$ \\
\hline Crohn’s disease [36 44] & $1.68-2.4$ & Crohn's disease [36] & 2.8 \\
\hline Ulcerative colitis $[36,44]$ & $3.3-4.5$ & & \\
\hline Duodenal ulcer [36] & 3.4 & Duodenal ulcer [36] & 1.9 \\
\hline Chronic pancreatitis [36] & 5.9 & Chronic pancreatitis [36] & 9.3 \\
\hline Liver flukes & & Liver flukes & \\
\hline Clonorchis sinensis infection $[38,42]$ & $8.6-13.6$ & Clonorchis sinensis infection [42] & 6.5 \\
\hline Endocrine disorders & & Endocrine disorders & \\
\hline Thyrotoxicosis [36] & 1.5 & Thyrotoxicosis [36] & 1.7 \\
\hline Diabetes mellitus type II [37-39,43,75,86] & $1.8-3.2$ & Diabetes mellitus type II $[35,36,45,86]$ & $1.5-3.2$ \\
\hline Metabolic conditions and general risks & & Metabolic conditions and general risks & \\
\hline Obesity $[36,44]$ & $1.7-1.71$ & & \\
\hline Alcohol intake $>80$ g/day $[37,39,75]$ & $1.52-5.21$ & Alcohol intake $>80$ g/day $[39,45]$ & $1.05-3.6$ \\
\hline Smoking $[36,44,162]$ & $1.3-2.1$ & Smoking [36] & 1.30 \\
\hline Metabolic syndrome [overall @ 44] & $1.32-1.83$ & Family history of other cancer [45] & 3.15 \\
\hline Dyslipoproteinemia [44] & 1.65 & & \\
\hline Hypertension [44] & 1.63 & & \\
\hline Chronic liver diseases & & Chronic liver diseases & \\
\hline Alcoholic liver disease $[36,44]$ & $3.1-5.69$ & Alcoholic liver disease [36] & 4.5 \\
\hline Non specific cirrhosis $[36,37,43,44,75]$ & $18.24-28.79$ & Non specific cirrhosis $[36,45]$ & $5.4-6.16$ \\
\hline Hemochromatosis [36] & 2.6 & & \\
\hline Hepatic schistosomiasis [43] & 11 & & \\
\hline Non alcoholic liver disease [36] & 3 & & \\
\hline Unspecified viral hepatitis [44] & 7.66 & & \\
\hline HCV infection $[77 \S, 36-40,44,75]$ & $2.41-9.71 ; 9.7 \S$ & HCV infection [78] & $1-3.05$ \\
\hline
\end{tabular}

(Contd...) 
Table 1 (Continued)

\begin{tabular}{|c|c|c|c|}
\hline $\begin{array}{l}\text { Risk factors for iCCA } \\
\text { [references] }\end{array}$ & $\begin{array}{l}\text { Odds ratios for } \\
\text { increased risk }\end{array}$ & $\begin{array}{l}\text { Risk factors for pCCA/dCCA } \\
\text { [references] }\end{array}$ & $\begin{array}{l}\text { Odds ratios for } \\
\text { increased risk }\end{array}$ \\
\hline HCV infection plus cirrhosis [40] & 8.53 & & \\
\hline HBsAg positive $\left[35,37-40,44,75,81^{\circ}\right]$ & $\begin{array}{c}2.3-9.7 \\
\circ 2.35-4.3\end{array}$ & HBsAg positive $\left[45,81^{\circ}\right]$ & $\begin{array}{c}1.84 \\
\circ 0.92-2.14\end{array}$ \\
\hline HBsAg positive plus cirrhosis $[35,40,41]$ & $13-18$ & HBsAg positive plus cirrhosis [45] & 3.42 \\
\hline \multirow[t]{7}{*}{$\mathrm{HBsAg}$ negative/HBcAb positive $\left[45,81^{\circ}\right]$} & $1.09-1.81^{\circ}$ & $\mathrm{HBsAg}$ negative/HBcAb positive $\left[45,81^{\circ}\right]$ & $\begin{array}{c}1.50 \\
0.88-1.24^{\circ}\end{array}$ \\
\hline & & ABO blood types & \\
\hline & & ABO blood type A [45] & 1.78 \\
\hline & & ABO blood type B [45] & 1.27 \\
\hline & & ABO blood type AB [45] & 0.44 \\
\hline & & ABO blood type and HbsAg positive [45] & 3.04 \\
\hline & & $\begin{array}{l}\text { ABO blood type A and HbsAg positive/ } \\
\mathrm{HBcAb} \text { positive [45] }\end{array}$ & 3.79 \\
\hline Occupational exposure & & Occupational exposure & \\
\hline Occupational exposure to asbestos [46] & 4.81 & Occupational exposure to asbestos [46] & 2.09 \\
\hline
\end{tabular}

*histological verified cases; \#histological verified cases comprise pCCA; \$iCCA cases comprise 2 cases of cHCC-CCA; @ according the 2001 U.S. NCEP-ATP III definition; ${ }^{\circ}$ Risk of CCA only in Asia

$C C A$, cholangiocarcinoma; $i C C A$, intrahepatic cholangiocarcinoma; $p C C A$, perihilar cholangiocarcinoma; $d C C A$, distal cholangiocarcinoma; HCV, hepatitis $C$ virus; PSC, primary sclerosing cholangitis

with iCCA and/or pCCA/dCCA (extrahepatic CCA), assessed by multivariate analyses. The case-control studies were selected from papers returned by the following search terms on PubMed: ("cholangiocarcinoma" [MeSH Terms] OR "cholangiocarcinoma" [All Fields]) AND ("risk factors" [MeSH Terms] OR ("risk" [All Fields] AND "factors" [All Fields]) OR "risk factors"[All Fields] OR ("risk"[All Fields] AND "factor" [All Fields]) OR "risk factor" [All Fields])) NOT ("review"[Publication Type] OR "review literature as topic"[MeSH Terms] OR "review"[All Fields]) AND English [lang]. The selection criteria also required that works include histologically verified case series of iCCA and/or pCCA/ dCCA with appropriate topographic classification (Klatskin tumors classified as pCCA and excluded from the iCCAs). In the 14 case-control studies selected, several putative risk factors were evaluated. The risk factors were collected based on the pathophysiological mechanisms leading to CCA (cells primarily targeted or activated by diseases and therefore involved in the carcinogenic process) and on the homogeneity of risk factors.

The investigated risk factors could be classified on the basis of the tissue or the cell primarily targeted by diseases or conditions and is therefore likely to be involved in the carcinogenic process as cell or tissue of origin. In this view, biliary diseases such as cholangitis/PSC, secondary biliary cirrhosis, choledocholithiasis, hepatolithiasis, cholecystitis and liver flukes are pathological conditions that primarily affect large intra- and/or extrahepatic bile ducts (Table 1) (Fig. 1). Appropriately, as shown in Table 1, these pathological conditions are risk factors for both iCCA and p/dCCA. Pancreaticobiliary maljunction, cholelithiasis, and cholecystectomy primarily affect extrahepatic bile ducts. Moreover, these conditions are recognized risk factors essentially for p/dCCA (Table 1) (Fig. 1). Parenchymal liver diseases, including chronic viral and non-viral liver diseases, recognize the interlobular bile ducts, bile ductules, and the canals of Hering as the primary targets; thus, these conditions are specific risk factors for iCCA (Table 1).

Moreover, several toxic and environmental risk factors are known or suspected to be related to CCA development; amongst them are nitrosamine-contaminated food, asbestos, dioxins, vinyl chlorides and, in the past, thorotrast [47]. However, the geographic distribution of the related CCA cases associated with these risk factors, and their combination with other identified factors or with subclinical inflammation of the liver and biliary tree (see obesity, metabolic diseases, steatosis), are largely unknown.

PSC, a disease affecting both intra- and extrahepatic bile ducts, represents the strongest independent risk factor for both iCCA and pCCA as evaluated by multivariate analysis (Table 1). Several other dated studies evaluated the cumulative risk of CCA in PSC patients, but not the discrete risk of iCCA and/or pCCA in PSC [48-51]. The lifetime incidence of CCA among PSC patients ranges from 5-10\% [52-55]. Clinicopathological observations suggested that PSC is specifically associated with the development of bile-duct (mucinous) type CCA $[4,56]$. We have indeed found a PSC-specific pathologic spectrum involving peribiliary glands (PBGs) in large bile ducts that exhibit cell proliferation in PBGs, mucinous metaplasia, epithelial mesenchymal transition (EMT) traits, and dysplasia, 
suggesting a carcinogenic progression linked with the manifestation of PSC within the bile ducts [56].

In addition, inflammatory bowel diseases (IBD) associated with or preceding PSC may significantly affect the risk of CCA. In a European multicenter study, the coexistence and duration of IBD significantly increased the risk of CCA in PSC patients [51] and the incidence of CCA was highest within the first year after diagnosis of IBD [51]. According to a recent meta-analysis of IBD patients, the estimated relative risk was 2.61 for iCCA versus 1.47 for pCCA [57]. Both Crohn's disease (CD) and ulcerative colitis (UC) were found to be associated with an increased risk of CCA, whereas CD patients seemed to have a lower risk of CCA than UC patients [57]. Recently, it has been revealed that CD and no IBD (both vs. UC) were associated with a lower risk of malignancy in PSC patients (hazard ratio, 0.77; $\mathrm{P}=0.004$ ) [58]. In contrast, in a US study neither IBD nor its duration conferred additional risk of CCA in PSC patients [59].

In another study, Welzel et al reported that duodenal ulcer disease was significantly more common among pCCA and iCCA cases than controls [36]. Many studies have demonstrated associations between CCA and Helicobacter pylori, but the correlation remains controversial and a direct causal relationship has not been established [60-66].

A positive association between chronic pancreatitis and CCA has also been found. The risk is greater in pCCA than in iCCA (Table 1).

A strong association exists between liver fluke infestation (Ophistorchis viverrini [OV] and Clonorchis sinensis) and the development of CCA, in particular in east Asia, where iCCA represents a large proportion of primitive liver cancers (Table 1) [67,68].

Some epidemiological studies have been conducted to evaluate the relationship between type 2 diabetes and CCA (Table 1) [36,69-71]. In this regard, it was demonstrated in a diabetes model and in human subjects affected by type 2 diabetes that PBGs underwent proliferation and expansion in relation to hyperglycemia [72]. Interestingly, metformin significantly reduced the risk of iCCA in diabetic patients by $60 \%[73,74]$. A recent meta-analysis also confirmed that obesity, alcohol use, and smoking have an association with iCCA [75].

In recent years, it is becoming more evident that metabolic conditions, particularly metabolic syndrome, predispose to the development of primary liver cancers $[3,44,76]$. Nonalcoholic fatty liver disease/nonalcoholic steatohepatitis (NAFLD/ $\mathrm{NASH}$ ) have been found to be independent predictors of iCCA development, though with a lower strength of association than other risk factors (viral hepatitis, cirrhosis), whereas NAFLD/ NASH failed to predict pCCA (Table 1). Hemochromatosis has also been identified as an independent predictor of iCCA development, though it failed to predict pCCA (Table 1).

It has long been known that the presence of cirrhosis increases the risk of iCCA [36,37,40,44,75]. Liver diseases related to hepatitis $\mathrm{B}$ virus ( $\mathrm{HBV}$ ) and hepatitis $\mathrm{C}$ virus (HCV) have been identified as definitive risk factors for CCA, with a stronger association for iCCA than pCCA [77]. A meta- analysis by Palmer et al of eight case-control studies indicated that HCV was associated with an overall odds ratio of 4.84 for iCCA [75]. Li et al have furthermore described that this infection was associated, not only with iCCA, but even with an increased risk of pCCA [78]. The association with HBV is more significant where the prevalence of the infection is higher, such as in Asian countries [79,80]. As regards HBV infection (HBsAg seropositivity), the range of the odds ratio in the positive study was from 2.3 to 9.7 (Table 1) [81]. The presence of cirrhosis in $\mathrm{HBV}$ or $\mathrm{HCV}$ patients increases the risk of CCA (Table 1): the risk of iCCA increased 2.5-fold (95\% confidence interval [CI] 1.2-5.1; $\mathrm{P}=0.02)$ in $\mathrm{HBV}$, and 3.2-fold (95\%CI 1.2-8.1, $\mathrm{P}=0.017)$ in HCV patients [41].

The burden of HCV in the last few decades has been associated with a specific increase in iCCA, as well as in HCC [81]. Likewise, clinicopathological observations suggest that liver cirrhosis is specifically associated with the development of small-bile-duct (mixed) type iCCA [4]. Ductular reaction is a marker strongly associated with the evolution of chronic liver disease in cirrhosis. The origin of small-bile-duct type iCCA may be associated with the chronic proliferative activation of hepatic stem cells and senescence of mature hepatocytes in chronic liver diseases $[12,82]$.

\section{Molecular profiling and the identification of multiple CCA subsets}

Enormous geographic and racial differences exist with CCA $[3,83]$. Generally, the prominent genetic alterations described in CCAs affect Tumor Protein 53 (TP53) (DNA repair) [84-86], tyrosine kinase (KRAS Proto-Oncogene, GTPase [KRAS], B-Raf Proto-Oncogene, Serine/Threonine Kinase [BRAF], Small Mother Against Decapentaplegic 4, and Fibroblast Growth Factor Receptor 2) [8,84-88], and and Protein Tyrosine Phosphatase, Non-Receptor Type 3 (PTPN3) [89], deregulated Wnt Family Member/Catenin Beta 1 (WNT/CTNNB1) [90] and Notch pathways, epigenetic (Isocitrate Dehydrogenase $(\mathrm{NADP}(+))$ 1, Cytosolic [IDH1] and Isocitrate Dehydrogenase $(N A D P(+)) 2$, Mitochondrial [IDH2]) [28,84,88,91,92], and chromatin-remodeling factors [85] (AT-Rich Interaction Domain 1A, Polybromo 1, and BRCA1 Associated Protein 1) [84,86,88,91].

Since all known CCA risk factors are associated with chronic bile duct inflammation, it is understandable that molecular studies have also focused on genetic/epigenetic abnormalities involving inflammation-related genes [93-95]. In keeping with the initiation and progression of CCA in the inflammatory milieu, the enzyme cyclooxygenase (COX)2 is induced in CCA by both bile acids and oxysterols, the oxidation products of cholesterol that are increased in the bile during biliary inflammation $[96,97]$. Inflammatory cytokines may also induce the expression of inducible nitric oxide (NO) synthase (iNOS) in CCA. NO promotes DNA damage directly and also by inhibiting DNA repair mechanisms, thus promoting carcinogenesis $[98,99]$. iNOS activation 
also stimulates the expression of COX-2 [100]. Interestingly, recurrent genetic variants in the promoter of human telomerase reverse transcriptase [88] have been described in CCA that developed in the chronic inflammation milieu of the hepatitis infection [88]. This molecular alternation could be correlated with the pivotal role of telomerase in controlling stem cells, extremely challenged in conditions of chronic inflammation because the senescence of the mature hepatocytes determines the secondary stem proliferative activation [12].

The comparative evaluation of the gene expression profile (transcriptome), clinicopathological traits, and patient outcomes in iCCA cases has allowed for the identification of two main biological classes of iCCA: 1) the inflammation class (38\%), characterized by activation of inflammatory signaling pathways, overexpression of cytokines, and Signal transducer and activator of transcription 3 activation; and 2) the proliferation class (62\%), characterized by activation of oncogenic signaling pathways (i.e., RAS, mitogen-activated protein kinase and hepatocyte growth factor [HGF]/MET), DNA amplifications at 11q13.2, deletions at 14q22.1, mutations in KRAS and BRAF and gene expression signatures previously associated with poor outcomes for patients with HCC [7].

Technological advances have also allowed the differential characterization of genomic and genetic features of CCA epithelial and stromal compartments [101]. The tumor epithelium was defined by deregulation of the Human Epidermal Growth Factor Receptor 2 network and frequent overexpression of Epidermal Growth Factor Receptor, HGF/ MET, Plastid Ribosomal Protein S6, and Ki67, whereas the stroma was rich in inflammatory cytokines [101].

The molecular mechanism of OV-associated CCA has been also studied in experimental models [32,102]. In humans, molecular studies of iCCA associated with liver flukes demonstrated an overexpression of genes involved in xenobiotic metabolism (UDP Glucuronosyltransferase Family 2 Member B11, UDP Glucuronosyltransferase Family 1 Member A10, Carbohydrate Sulfotransferase 4, Sulfotransferase Family $1 C$ Member 2), whereas, in contrast, non-OV-associated iCCA showed enhanced expression of genes related to growth factor signaling (Transforming Growth Factor $\beta 1$, Placental Growth Factor, Insulin Like Growth Factor-Binding Protein). The draft genome of Clonorchis sinensis and transcriptomes of Clonorchis sinensis and OV have recently been elucidated [103,104]. In a large cohort of iCCA $(n=102)$ associated with liver fluke infection, promoter hypermethylation in a handful of target genes was demonstrated [105]. Thus, the evaluation of the putative signature of liver flukes associated with CCA could help in screening and surveillance, with the perspective of an early diagnosis in subjects carrying the infestation [102].

CCA genetic susceptibility has been investigated in geographic areas where liver flukes are endemic. In these studies, specific haplotypes of COX2-coding gene Prostaglandin-Endoperoxide Synthase 2 (PTGS2) or Interlukin 8 Receptor Beta (IL8RB) have recently been associated with a significant risk of CCA development [106].

Different molecular signatures of the high oncogenic risk were described in PSC patients. KRAS mutations were found in the bile fluid of $30 \%$ of PSC patients without evidence of CCA [107]. Since KRAS mutations are frequently observed in CCA, this could be an early event of bile-duct carcinogenesis in PSC patients. Notably, mutational profiling can be performed in cell-free DNA of bile supernatant [108]. The inflammatory microenvironment has also been associated with an aberrant DNA methylation profile in PSC-derived CCA, which provides survival signals for the tumor [109]. Genetic susceptibility of PSC patients to CCA development was demonstrated by studies concerning the natural killer cell G2D receptor, where specific genetic variants have been described in PSC patients [110].

As far as multilevel differences between iCCA and pCCA are concerned, it has been shown that pCCA expresses higher levels of Mucin 5AC, AKT Serin/Theronin Kinase, Keratin 8, and Annexin, but less Vascular Endothelial Growth Factor. At a molecular level, distinct patterns of genetic mutations, methylation, and expression profiling may differentiate iCCA from pCCA. iCCAs were significantly more frequently B-cell Lymphoma 2+ and p16+, whereas pCCAs were more often Tumor Protein p53+ [111]. Miller et al revealed 545 genes with altered expression in p/dCCA and 2354 in iCCA [112]. Mutations in IDH1 and IDH2 were found only in iCCA $(n=9)$, but in none of the examined p/dCCA $(n=22)$ and gallbladder cancer $(n=75)$ cases [113]. Recent papers confirmed that liver-fluke-negative iCCAs are enriched with IDH mutants [14,28]. A cross-platform comparison of CCA with pancreatic cancer and HCC further emphasized the presence of distinct tumor subsets, suggesting similarities between IDH-mutant CCAs and HCCs, rather than pancreatic cancers [28]. Conversely, mutations in KRAS by tumor site demonstrated a predominance of KRAS mutations in pCCAs (53.3\% of hilar vs. $6.7 \%$ of peripheral type) [7]. As far as epigenetic abnormalities are concerned, the methylation of Ras Association Domain-Containing Protein 1 (RASSF1A) was more common in pCCA than in iCCA, while the opposite was demonstrated for the methylation of the Glutatione $S$-Transferase P (GSTP) gene [114]. Other reported alterations associated with iCCA included fibroblast growth factor receptor pathways and Ephrin Type-A Receptor 2 (EPHA2) mutations [115].

Finally, the histopathological distinction of cholangiolocellular differentiation of iCCA has been correlated with its genome-wide molecular features and clinical significance [115]. Based on cholangiolocellular differentiation status, iCCAs were stratified into iCCA with or without cholangiolocellular differentiation. iCCA with cholangiolocellular differentiation resembling an inflammation-related subtype revealed less aggressive histopathological features compared to iCCA without cholangiolocellular differentiation resembling a proliferation subtype. Accordingly, the former showed more favorable clinical outcomes, including overall survival, than iCCA without cholangiolocellular differentiation [116]. An updated expert review of a personalized approach based on molecular target therapies in CCA has recently been published [117]. 


\section{Variable clinical presentations and diagnostic features}

The clinical presentation of CCA is largely influenced by anatomic location and pattern of growth, which depend on the cells of origin. Recent studies on the origin of CCA have demonstrated that CCA comprises at least two separate entities with distinct histology, progression, and risk factors. These subtypes have recently been classified into large-bileduct (mucinous) type CCAs and small-bile-duct or mixed CCAs. According to multiple observations, pCCAs most likely originate from mucin-secreting cholangiocytes and PBGs [118] located in hilar bile ducts, show a large-bileduct (mucinous) type histology, and are associated with preneoplastic lesions emerging in surface epithelium [2,3] and PBGs [118]. On the other hand, iCCAs show intertumor heterogeneity and are classified into two main different histological subtypes [4,119], which probably have different cells of origin [4]: the small-bile-duct or mixed CCA and the-large-bile duct (mucinous) type iCCAs [22,119]. This last iCCA subtype displays an immunohistochemistry (IHC), gene expression and clinicopathological profile that can be superimposed on pCCA [4,120-122]. Small-bile-duct or mixed CCAs usually show a peripheral localization and an MF growth pattern. In contrast, large-bile-duct (mucinous) type CCAs usually show a periductal infiltrating and/or MF growth pattern [4]. Importantly, these separate entities differ in prognosis (with the mucin-producing iCCAs having a worse prognosis) and in associated diseases [4,10,82,123]. Indeed, parenchymal liver diseases, including chronic viral and non-viral liver diseases and liver cirrhosis, should be considered risk factors for mixed-type iCCAs [4,10,82,123]. In contrast, chronic biliary diseases or pathologies and conditions affecting the intrahepatic medium-large and extrahepatic bile ducts are risk factors for mucin-producing iCCAs and pCCAs $[4,10,82,123]$. These differences significantly affect the clinical presentation and modalities of diagnosis $[4,10,82,123]$. As far as the mixed-type MF iCCA is concerned, the clinical presentation is similar to that of other intrahepatic liver malignancies, but different from that of pCCA $[4,10,82,123]$. CCAs are usually asymptomatic in their early stages (20-25\% of cases are incidental findings). Malaise, cachexia, abdominal pain, night sweats, fatigue and/or jaundice, whether associated or not with systemic manifestations, represent the clinical onset of symptomatic iCCA $[4,10,82,123]$. In contrast, a typically painless jaundice is the most frequent clinical onset in pCCA $[4,10,82,123]$. Regarding patients with PSC, CCA may present as the development of a rapid deterioration of clinical conditions or dominant stricture during follow up [3]. In general, the MF type represents the most frequent macroscopic presentation of iCCA $(>90 \%)$, appearing on imaging as a nodule $[3,123]$. In the context of cirrhotic liver, it was demonstrated that, in contrast-enhanced magnetic resonance imaging (MRI), iCCAs consistently showed a lack of HCC hallmarks, though in computed tomography this occurs only in large nodules $(>3 \mathrm{~cm})$ [124-126]. Currently, the identification of HCC with stem-cell features (CK19+-HCC), combined HCC-CCA, cholangiolocellular carcinoma and bile-duct mixed type iCCA with imaging procedures is still an unsolved challenge $[3,4,10,123,127,128]$. Biopsy is therefore necessary after excluding HCC in cirrhosis, or in the context of a nodule in a non-cirrhotic liver [3,129]. From a histological point of view, the differential diagnosis of iCCA versus HCC or metastasis represents an unsolved problem $[2,3,129,130]$, partly because of the lack of validation of specific markers.

Radiologically, pCCA usually appears as a dominant stricture; therefore, MRI+MRCP represents the imaging procedure with the highest diagnostic accuracy for localizing and sizing the stricture [3], though the definitive demonstration of malignancy is still a challenge [3]. In this respect, endoscopic retrograde cholangiopancreatography enables a number of procedures that may allow microscopic confirmation, including cytology, brushing, fluorescent in situ hybridization (FISH)-polysomy, biopsy, or further innovative techniques [3]. However, all these techniques have an unsatisfactory sensitivity [54,130-133], and even FISHpolysomy demonstrated a low sensitivity for detecting CCA in PSC patients in a meta-analysis [133]. Essentially, the diagnosis of CCA still requires a combination of clinical, radiological and non-specific histological/biochemical markers [3].

\section{Cells of origin and cancer stem cells: inter- and intratumoral heterogeneity}

The cell of origin, or cancer-initiating cell, is considered to be the normal cell that receives the first cancer-causing mutation [134,135]. On the other hand, cancer stem cells (CSCs) are the cells that sustain tumor growth and propagation $[134,135]$. Therefore, the phenotypes of cells of origin and CSCs may be substantially different $[134,135]$.

CCA subtypes exhibit pronounced heterogeneity, raising the question of potentially diverse cellular origins [4,9-12]. Possible cells of origin are human Hepatic stem/progenitor cells (hHpSCs), immature neural cell adhesion molecule positive (NCAM+) cholangiocytes, mature (NCAM-) interlobular cholangiocytes, and PBGs (Fig. 1) [10]. According to different observations, pCCAs most probably originate from mucin-secreting cholangiocytes and PBGs [56,118] located in hilar bile ducts. Indeed, pCCAs are associated with preneoplastic lesions emerging in surface epithelium [2,3] and PBGs $[56,118]$. Moreover, the IHC and gene expression profiling of pCCA have shown a strong similarity to the cylindrical, taller, mucin-producing cholangiocytes (and PBGs) lining hilar bile ducts $[4,118,136]$. On the other hand, iCCAs show inter-tumor heterogeneity, leading to their classification into two main different histological subtypes [4,119], most probably with different cells of origin [4]. The large bile duct (mucinous) type iCCAs arise in larger intrahepatic bile ducts; this portion of the intrahepatic biliary tree shares anatomical and embryological similarities with the extrahepatic biliary tree and pancreatic duct system [22,119]. This iCCA subtype displays IHC, gene expression and a clinicopathological 
profile that can be superimposed on pCCA [4]; in addition, it displays (together with pCCA) large similarities to pancreatic ductal adenocarcinoma [120-122]. The pattern of growth and the presence of preneoplastic lesions in cholangiocytes and PBGs lining larger intrahepatic bile ducts identify these cells as candidate cells of origin [56,136]. The small bile duct (mixed) type iCCAs show an IHC and gene expression profile similar to mucin-negative cuboidal cholangiocytes that line the smaller bile duct (interlobular bile duct and bile ductules) [4]. In addition, the phenotypic and genotypic profiles are similar to those of cholangiolocellular carcinoma thought to originate from hepatic progenitor cells $[4,137,138]$. A number of observations suggest that small bile duct (mixed) type iCCAs, together with cholangiolocellular carcinoma and CK19+ HCC, represent a group of primitive liver cancers originating from hHpSCs [4,21,139-141]. Thus, a unique feature of CCA is that it recognizes as origin tissues the hepatic parenchyma or large bile ducts, furnished by two distinct stem cell niches, the canals of Hering and the PBGs, respectively (Fig. 2) [12].

Based on the grade of maturation of the cell of origin within the two lineages, our suggestion is that CCAs could be classified as (Fig. 2):
- Primary liver parenchymal CCA: cholangiolo-carcinoma, small-bile-duct type (mixed) CCA, and combined HCCCCA. These tumors emerge within the liver parenchyma from the canals of Hering, bile ductules and interlobular bile ducts and indeed originate from hHpSCs, immature $\mathrm{NCAM}+$ cholangiocytes, or mature (NCAM-) interlobular cholangiocytes.

- Primary biliary CCA: dCCA, pCCA, and large-bile-duct (mucinous) type iCCA. These tumors emerge from the extrahepatic biliary tree and larger intrahepatic bile ducts and originate from PBGs or the surface epithelium of corresponding bile ducts.

CSCs are defined as the cells within a tumor that possess the capacity for self-renewal and generation of heterogeneous lineages. CSCs are highly tumorigenic and are responsible for chemo-radio resistance and tumor recurrence $[137,142,143]$. Several CSC markers have been reported in human CCAs [137], including CD133 [144], epithelial cell adhesion molecule (EpCAM) [145], CD44 [146], CD13 [147] and CD90 [148]. In a recent study, CSCs comprised more than $30 \%$ of the tumor mass in human CCA sub-types [120]. Interestingly, the CSC profile was similar between mucinous iCCA and pCCA [120].

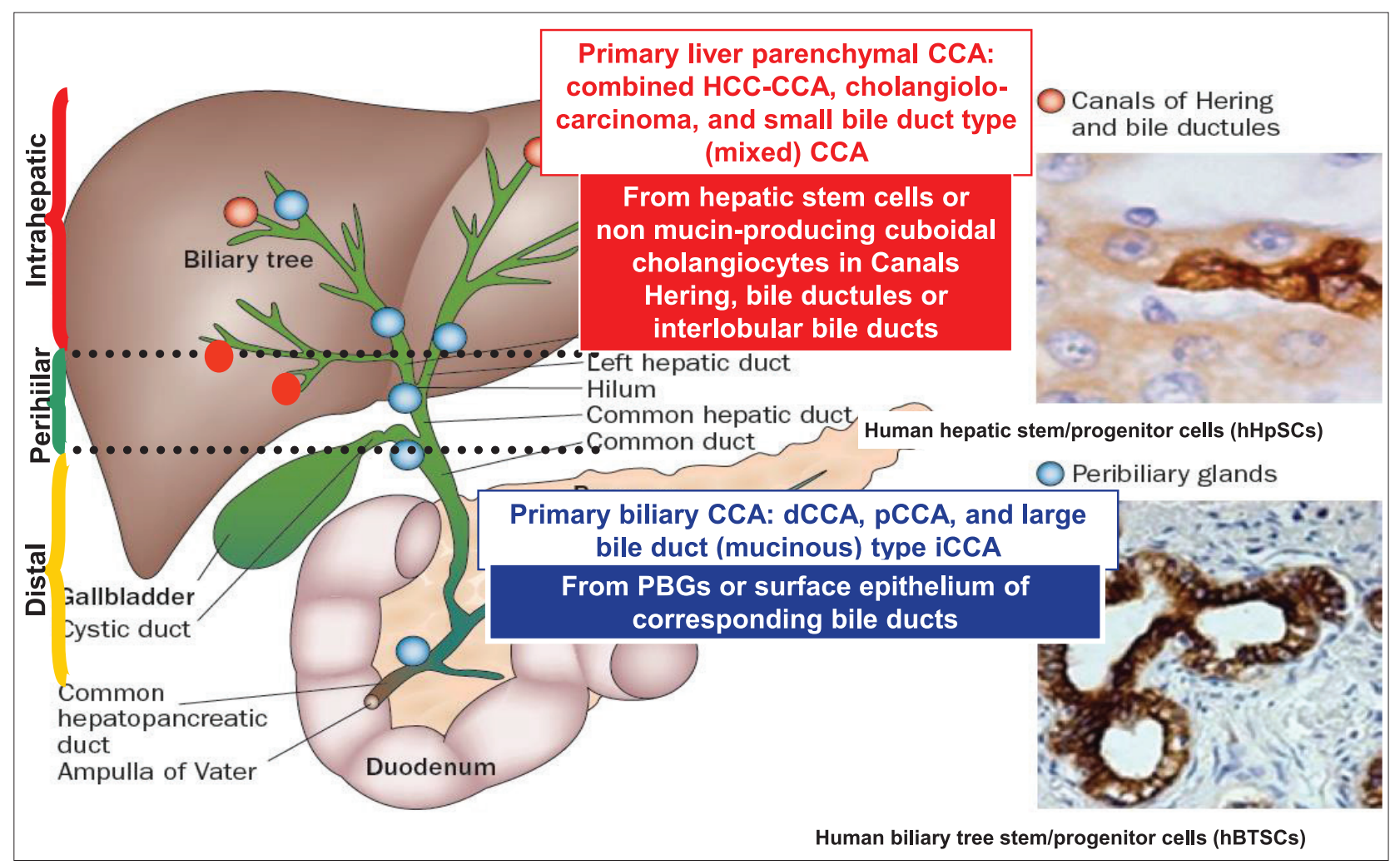

Figure 2 Classification of cholangiocarcinoma based on cell lineages of origin.

Based on the grade of maturation of the cell of origin within the two lineages, one constituted by the hepatic stem cells and non mucin-producing cuboidal cholangiocytes in Hering canals and bile ductules/interlobular bile ducts (see red points), the other constituted by peribiliary glands (PBGs) and surface epithelium of corresponding bile ducts (see blue points), our suggestion is that CCAs could be reclassified as:

- primary liver parenchymal CCA comprising combined HCC-CCA, cholangiolo-carcinoma, and small-bile-duct type (mixed) CCA

- primary biliary CCA comprising dCCA, pCCA, and large-bile-duct (mucinous) type iCCA

Modified from Cardinale et al. Nat Rev Gastroenterol Hepatol [ref. 119] 
Clinicopathological studies demonstrated the expression of cluster of designation (CD133) [34], Epithelial cell adhesion molecule (EpCAM) [35], CD44 and SRY-related HMG-box(Sox2)[146], and S100 calcium-binding protein A4 (S100A4) EMT marker [13,149] as being significant contributors to the worsening of CCA prognosis. EpCAM and CD133 are expressed by microparticles in a liquid biopsy of CCA patients and showed significant diagnostic and prognostic potential [150]. Moreover, Sox17, a biliopancreatic progenitor transcriptional factor that regulates the differentiation and maintenance of the biliary phenotype, acts as a tumor suppressor in CCA and its restoration may represent a promising new therapeutic strategy [151].

Vital stem-cell signaling pathways, especially Notch, Wnt/ $\beta$-catenin or Hedgehog, are crucial players in CCA pathogenesis $[137,138]$ and could serve as molecular targets, contributing to efficient CSC target therapy [152,153]. However, CSC markers and signaling pathways are largely shared by normal and cancer stem cells, thus limiting targeted strategies specific to CSCs in primary liver cancers $[137,151,153]$. Moreover, CSCs display considerable crosstalk and redundancy in signaling pathways $[152,153]$.

Cancers that follow the stem cell model are also subject to clonal evolution, as well as heterogeneity from environmental differences within tumors $[154,155]$. Specifically, genetically distinct subclones, together with developmental pathways and epigenetic modifications, can contribute to functional heterogeneity [155]. In CCA, the tumor microenvironment is composed of cancer-associated macrophages, fibroblasts, and vascular cells and functions as a specialized CSC niche, thus contributing to the maintenance of stemness and chemoresistance $[138,149,155-157]$. Many factors needed for the maintenance of CSC within its niche (cellular components, soluble factors, cytokines and growth factors) [138,157], should be considered additional potential targets for successful therapeutic strategies against CSC $[152,153,157,158]$.

Human CCA cells expressed EMT markers both in situ and in vitro and, interestingly, subcutaneous xenografts from highly tumorigenic CD90+ or CD13+ CSCs were dominated by stromal markers [120]. By contrast, in intrahepatic xenografts in cirrhotic livers, tumors were dominated by epithelial traits reproducing the original human CCAs, suggesting that CSC subpopulations generate different types of cancer, depending on the microenvironment [120]. A similar phenomenon was described at the single-cell level in breast cancer, where metastatic cells from low-burden tissues were individuated by their increased expression of stem cell, EMT, prosurvival, and dormancy-associated genes with respect to high-burden metastasis, which is constituted by differentiated tumor cells [159]. The increased expression of stem and EMT genes in CCAs may imply a process of metastasis that could be determined by circulating tumor cells, characterized by an intermediate phenotype that is largely unknown and represents a research target with important clinical implications.

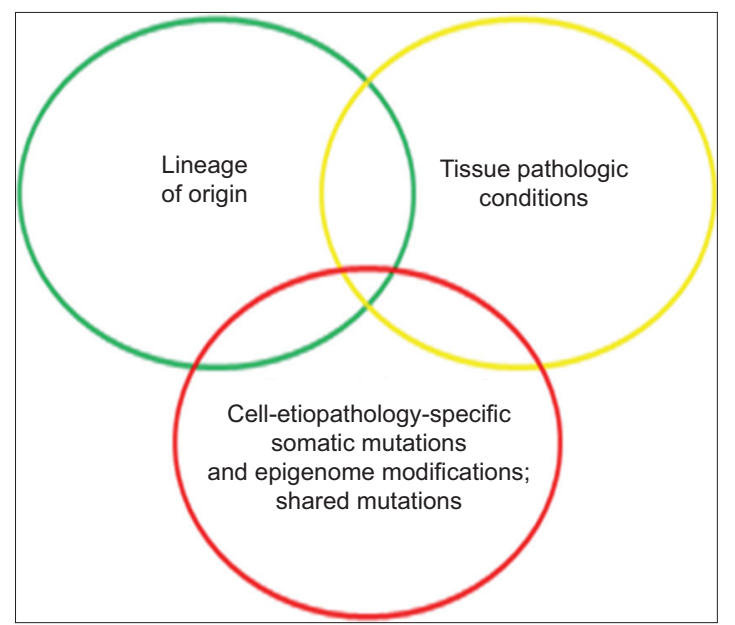

Figure 3 We suggest a model of cholangiocarcinogenesis in which the interplay among the lineage of origin, the pathologic conditions, and the cell-etiopathology-specific somatic mutations and epigenetic modifications ( $+/$ - shared mutations) determines multiple patterns of cholangiocarcinogenesis

\section{Concluding remarks}

Regarding the origin of CCA, a physiopathology concept that emphasizes the lineage of origin over the cell of origin should be considered (Fig. 2) [10,12,13,148]. A CCA classification based on the cell lineages of origin is more consistent with current knowledge regarding epidemiology and risk factors and may have important clinical implications in the definition of specific therapeutic targets (Fig. 2). Moreover, it highlights a lineage dependency of chronic liver diseases and related molecular carcinogenesis [12]. Since somatic mutagenesis and epigenome features are cell/lineage specific [160] and are largely driven by the preneoplastic pathologic milieu (see inflammation) (Fig. 3), the multiple lineages of origin plus the related diseases may explain the intertumoral heterogeneity observed at any level of CCA (Fig. 4). Emphasizing cell lineage in CCA development would have implications for preventive strategies in patients with clinical or subclinical underlying hepatic or biliary diseases, diagnosis and therapy (Fig. 4).

\section{Acknowledgments}

We kindly thank Prof. Domenico Alvaro for the mentorship and critical revision of the manuscript and for important intellectual contents informing largely this manuscript. We kindly thank Prof. Guido Carpino for critical revision of the paper and for important intellectual content and suggestions regarding CCA cells of origin, histomorphology and the proposal for the classification of CCA based on cells of origin. We thank Prof. Lola M. Reid for the background informing the intellectual content on stem cell populations of the liver and biliary tree in this article. We thank Dr. Gemma Mendel for providing the original artwork for Fig. 1 in this article. The 


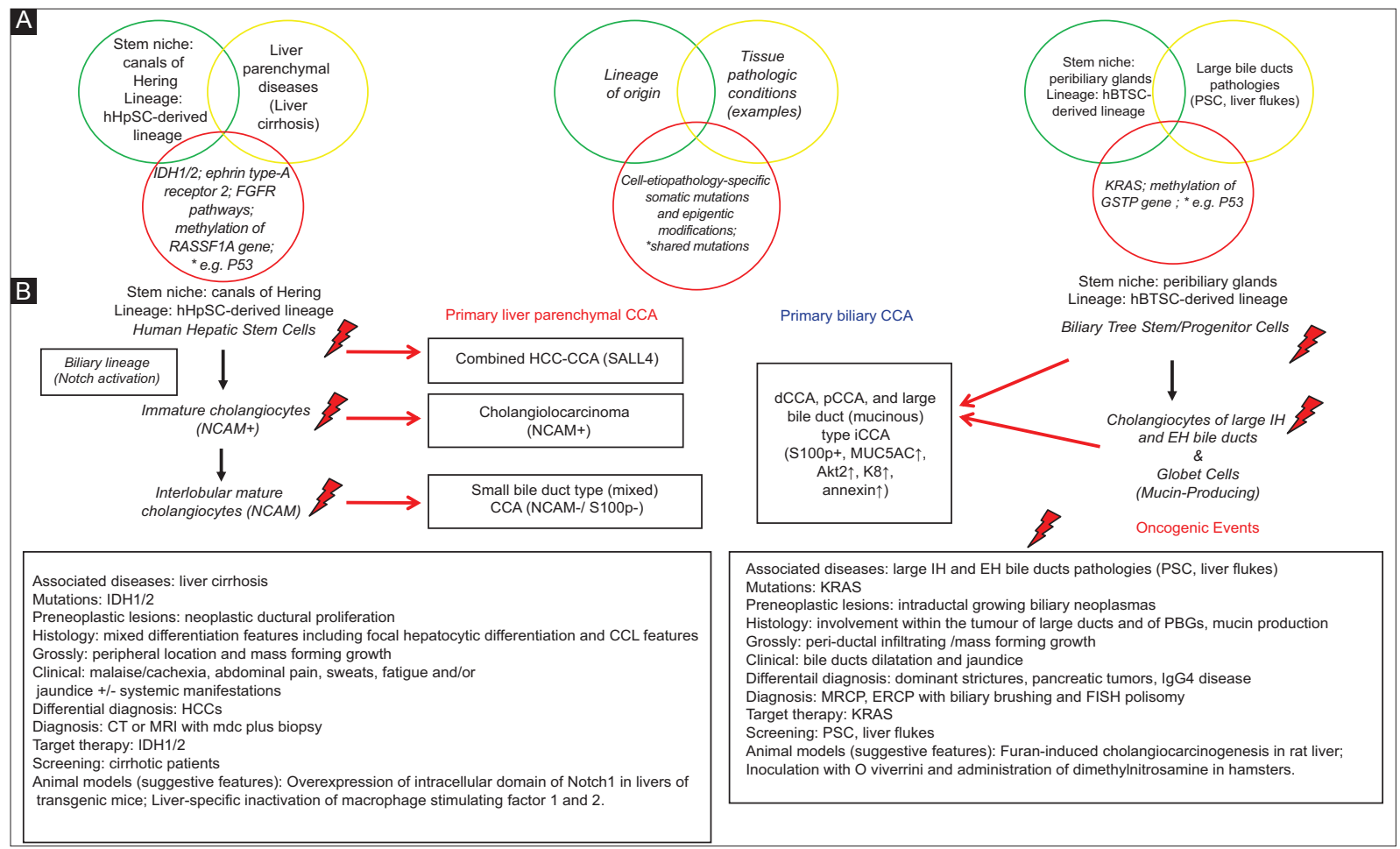

Figure 4 Origin and multilevel repercussions of the CCA heterogeneity.

A. The anatomical-functional heterogeneity of the biliary tree may explain the intertumoral heterogeneity observed at any level in CCA. Somatic mutagenesis and epigenetic features are cell/lineage type-specific, and largely driven by the preneoplastic tissue pathologic milieu (see inflammation). These are tissue-specific. Indeed, pathologic conditions targeting liver parenchyma are chronic hepatitis, nonalcoholic steatohepatitis, and primary biliary cholangitis, while pathologic conditions targeting the bile ducts are primary sclerosing cholangitis and liver flukes.

B. Cells arising from a hHpSC lineage (left) or from a biliary tree stem/progenitor cell (hBTSC) lineage (right) are considered cells of origin of different intrahepatic (i)- and perihilar (p)-cholangiocarcinoma (CCA) subtypes that were recently described. In the boxes, clinicopathological features, histology, gross and clinical features, associated diseases, management, prominent somatic mutations and candidate experimental models of the CCA subtypes arising within the two cell lineages are shown

HCC, hepatocellular carcinoma;

CLC, cholangiolo-carcinoma

authors thank the native English speaker and teacher Melissa Kerr for English language revision.

\section{References}

1. Bridgewater J, Galle PR, Khan SA, et al. Guidelines for the diagnosis and management of intrahepatic cholangiocarcinoma. $J$ Hepatol 2014;60:1268-1289.

2. Blechacz B, Komuta M, Roskams T, Gores GJ. Clinical diagnosis and staging of cholangiocarcinoma. Nat Rev Gastroenterol Hepatol 2011;8:512-522.

3. Banales JM, Cardinale V, Carpino G, et al. Expert consensus document: Cholangiocarcinoma: current knowledge and future perspectives consensus statement from the European Network for the Study of Cholangiocarcinoma (ENS-CCA). Nat Rev Gastroenterol Hepatol 2016;13:261-280.

4. Komuta M, Govaere O, Vandecaveye V, et al. Histological diversity in cholangiocellular carcinoma reflects the different cholangiocyte phenotypes. Hepatology 2012;55:1876-1888.

5. Aishima S, Oda Y. Pathogenesis and classification of intrahepatic cholangiocarcinoma: different characters of perihilar large duct type versus peripheral small duct type. J Hepatobiliary Pancreat Sci 2015;22:94-100.

6. Rizvi S, Gores GJ. Pathogenesis, diagnosis, and management of cholangiocarcinoma. Gastroenterology 2013;145:1215-1229.

7. Andersen JB, Spee B, Blechacz BR, et al. Genomic and genetic characterization of cholangiocarcinoma identifies therapeutic targets for tyrosine kinase inhibitors. Gastroenterology 2012;142:1021-1031.

8. Nakamura H, Arai Y, Totoki Y, et al. Genomic spectra of biliary tract cancer. Nat Genet 2015;47:1003-1010.

9. Nakanuma Y, Sato Y, Harada K, Sasaki M, Xu J, Ikeda H. Pathological classification of intrahepatic cholangiocarcinoma based on a new concept. World J Hepatol 2010;2:419-427.

10. Cardinale V, Carpino G, Reid L, Gaudio E, Alvaro D. Multiple cells of origin in cholangiocarcinoma underlie biological, epidemiological and clinical heterogeneity. World J Gastrointest Oncol 2012;4:94-102.

11. Cardinale V, Bragazzi MC, Carpino G, et al. Cholangiocarcinoma: increasing burden of classifications. Hepatobiliary Surg Nutr 2013;2:272-280.

12. Lanzoni G, Cardinale V, Carpino G. The hepatic, biliary, and pancreatic network of stem/progenitor cell niches in humans: A new reference frame for disease and regeneration. Hepatology 2016;64:277-286. 
13. Gu MJ, Jang BI. Clinicopathologic significance of Sox2, CD44 and CD44v6 expression in intrahepatic cholangiocarcinoma. Pathol Oncol Res 2014;20:655-660.

14. Akita M, Fujikura K, Ajiki T, et al. Dichotomy in intrahepatic cholangiocarcinomas based on histologic similarities to hilar cholangiocarcinomas. Mod Pathol 2017;30:986-997.

15. Yamasaki S. Intrahepatic cholangiocarcinoma: macroscopic type and stage classification. I Hepatobiliary Pancreat Surg 2003;10:288-291.

16. Alvaro D, Bragazzi MC, Benedetti A, et al; AISF "Cholangiocarcinoma" committee. Cholangiocarcinoma in Italy: A national survey on clinical characteristics, diagnostic modalities and treatment. Results from the "Cholangiocarcinoma" committee of the Italian Association for the Study of Liver disease. Dig Liver Dis 2011;43:60-65.

17. De Rose AM, Cucchetti A, Clemente G, et al. Prognostic significance of tumor doubling time in mass-forming type cholangiocarcinoma. J Gastrointest Surg 2013;17:739-747.

18. Farges O, Fuks D, Le Treut YP, et al. AJCC $7^{\text {th }}$ edition of TNM staging accurately discriminates outcomes of patients with resectable intrahepatic cholangiocarcinoma: By the AFC-IHCC-2009 study group. Cancer 2011;117:2170-2177.

19. Liau JY, Tsai JH, Yuan RH, Chang CN, Lee HJ, Jeng YM. Morphological subclassification of intrahepatic cholangiocarcinoma: etiological, clinicopathological, and molecular features. Mod Pathol 2014;27:1163-1173.

20. Nakanuma Y, Xu J, Harada K, et al. Pathological spectrum of intrahepatic cholangiocarcinoma arising in non-biliary chronic advanced liver diseases. Pathol Int 2011;61:298-305.

21. Komuta M, Spee B, Vander Borght S, et al. Clinicopathological study on cholangiolocellular carcinoma suggesting hepatic progenitor cell origin. Hepatology 2008;47:1544-1556.

22. Carpino G, Cardinale V, Onori P, et al. Biliary tree stem/progenitor cells in glands of extrahepatic and intraheptic bile ducts: an anatomical in situ study yielding evidence of maturational lineages. $J$ Anat 2012;220:186-199.

23. Theise ND, Saxena R, Portmann BC, et al. The canals of Hering and hepatic stem cells in humans. Hepatology 1999;30:1425-1433.

24. Kuwahara R, Kofman AV, Landis CS, Swenson ES, Barendswaard E, Theise ND. The hepatic stem cell niche: identification by labelretaining cell assay. Hepatology 2008;47:1994-2002.

25. Schmelzer E, Zhang L, Bruce A, et al. Human hepatic stem cells from fetal and postnatal donors. J Exp Med 2007;204:1973-1987.

26. Cardinale V, Wang Y, Carpino G, et al. Multipotent stem/progenitor cells in human biliary tree give rise to hepatocytes, cholangiocytes, and pancreatic islets. Hepatology 2011;54:2159-2172.

27. Turner R, Lozoya O, Wang Y, et al. Human hepatic stem cell and maturational liver lineage biology. Hepatology 2011;53:1035-1045.

28. Farshidfar F, Zheng S, Gingras MC, et al; Cancer Genome Atlas Network. Integrative Genomic Analysis of Cholangiocarcinoma Identifies Distinct IDH-Mutant Molecular Profiles. Cell Rep 2017; 18:2780-2794.

29. Fitzmaurice C, Dicker D, Pain A, et al; Global Burden of Disease Cancer Collaboration. The global burden of cancer 2013. JAMA Oncol 2015;1:505-527.

30. Poomphakwaen K, Asian Pac J Cancer Prev, et al. Risk factors for cholangiocarcinoma in Khon Kaen, Thailand: a nested casecontrol study. Asian Pac J Cancer Prev 2009;10: 251-258.

31. Shin HR, Oh JK, Masuyer E, et al. Comparison of incidence of intrahepatic and extrahepatic cholangiocarcinoma-focus on East and South-Eastern Asia. Asian Pac J Cancer Prev 2010;11:1159-1166.

32. Sripa B, Kaewkes S, Sithithaworn P, et al. Liver fluke induces cholangiocarcinoma. PLoS Med 2007;4:e201.

33. Gatta G, van der Zwan JM, Casali PG, et al; RARECARE working group. Rare cancers are not so rare: the rare cancer burden in Europe. Eur J Cancer 2011;47:2493-2511.

34. Donato F, Gelatti U, Tagger A, et al. Intrahepatic cholangiocarcinoma and hepatitis C and B virus infection, alcohol intake, and hepatolithiasis: a case-control study in Italy. Cancer Causes Control 2001;12:959-964.

35. Tao LY, He XD, Qu Q, et al. Risk factors for intrahepatic and extrahepatic cholangiocarcinoma: a case-control study in China. Liver Int 2010;30:215-221.

36. Welzel TM, Graubard BI, El-Serag HB, et al. Risk factors for intrahepatic and extrahepatic cholangiocarcinoma in the United States: a population-based case-control study. Clin Gastroenterol Hepatol 2007;5:1221-1228.

37. Yamamoto S, Kubo S, Hai S, et al. Hepatitis C virus infection as a likely etiology of intrahepatic cholangiocarcinoma. Cancer Sci 2004;95:592-595.

38. Lee TY, Lee SS, Jung SW, et al. Hepatitis B virus infection and intrahepatic cholangiocarcinoma in Korea: a case-control study. Am J Gastroenterol 2008;103:1716-1720.

39. Shaib YH, El-Serag HB, Nooka AK, et al. Risk factors for intrahepatic and extrahepatic cholangiocarcinoma: a hospitalbased case-control study. Am J Gastroenterol 2007;102:1016-1021.

40. Zhou YM, Yin ZF, Yang JM, et al. Risk factors for intrahepatic cholangiocarcinoma: a case-control study in China. World $J$ Gastroenterol 2008;14:632-635.

41. Lee CH, Chang CJ, Lin YJ, Yeh CN, Chen MF, Hsieh SY. Viral hepatitis-associated intrahepatic cholangiocarcinoma shares common disease processes with hepatocellular carcinoma. $\mathrm{Br} \mathrm{J}$ Cancer 2009; 100:1765-1770.

42. Choi D, Lim JH, Lee KT, et al. Cholangiocarcinoma and Clonorchis sinensis infection: a case-control study in Korea. J Hepatol 2006;44:1066-1073.

43. Zhou H, Wang H, Zhou D, et al. Hepatitis B virus-associated intrahepatic cholangiocarcinoma and hepatocellular carcinoma may hold common disease process for carcinogenesis. Eur J Cancer 2010;46:1056-1061.

44. Welzel TM, Graubard BI, Zeuzem S, El-Serag HB, Davila JA, McGlynn KA. Metabolic syndrome increases the risk of primary liver cancer in the United States: a study in the SEER-Medicare database. Hepatology 2011;54:463-471.

45. Zhou Y, Zhou Q, Lin Q, et al. Evaluation of risk factors for extrahepatic cholangiocarcinoma: $\mathrm{ABO}$ blood group, hepatitis $\mathrm{B}$ virus and their synergism. Int J Cancer 2013;133:1867-1875.

46. Brandi G, Di Girolamo S, Farioli A, et al. Asbestos: a hidden player behind the cholangiocarcinoma increase? Findings from a casecontrol analysis. Cancer Causes Control 2013;24:911-918.

47. Patel T. Cholangiocarcinoma-controversieses and challenges. Nat Rev Gastroenterol Hepatol 2011;8:189-200.

48. Broomé U, Olsson R, Lööf L, et al. Natural history and prognostic factors in 305 Swedish patients with primary sclerosing cholangitis. Gut 1996;38:610-615.

49. Farrant JM, Hayllar KM, Wilkinson ML, et al. Natural history and prognostic variables in primary sclerosing cholangitis. Gastroenterology 1991;100:1710-1717.

50. Rosen CB, Nagorney DM, Wiesner RH, Coffey RJ Jr, LaRusso NF. Cholangiocarcinoma complicating primary sclerosing cholangitis. Ann Surg 1991;213:21-25.

51. Erichsen R, Jepsen P, Vilstrup H, Ekbom A, Sørensen HT. Incidence and prognosis of cholangiocarcinoma in Danish patients with and without inflammatory bowel disease: a national cohort study, 1978-2003. Eur J Epidemiol 2009;24:513-520.

52. Chapman MH, Webster GJ, Bannoo S, Johnson GJ, Wittmann J, Pereira SP. Cholangiocarcinoma and dominant strictures in patients with primary sclerosing cholangitis: a 25 -year singlecentre experience. Eur J Gastroenterol Hepatol 2012;24:1051-1058. 
53. Bergquist A, Ekbom A, Olsson R, et al. Hepatic and extrahepatic malignancies in primary sclerosing cholangitis. J Hepatol 2002;36:321-327.

54. Chapman R, Fevery J, Kalloo A, et al; American Association for the Study of Liver Diseases. Diagnosis and management of primary sclerosing cholangitis. Hepatology 2010;51:660-678.

55. Claessen MM, Vleggaar FP, Tytgat KM, Siersema PD, van Buuren HR. High lifetime risk of cancer in primary sclerosing cholangitis. J Hepatol 2009;50:158-164.

56. Carpino G, Cardinale V, Renzi A, et al. Activation of biliary tree stem cells within peribiliary glands in primary sclerosing cholangitis. J Hepatol 2015;63:1220-1228.

57. Huai JP, Ding J, Ye XH, Chen YP. Inflammatory bowel disease and risk of cholangiocarcinoma: evidence from a metaanalysis of population-based studies. Asian Pac J Cancer Prev 2014;15:3477-3482.

58. Weismüller TJ, Trivedi PJ, Bergquist A, et al; International PSC Study Group.Patient age, sex, and inflammatory bowel disease phenotype associate with course of primary sclerosing cholangitis. Gastroenterology 2017;152:1975-1984.

59. Tyson GL, El-Serag HB. Risk factors for cholangiocarcinoma. Hepatology 2011;54:173-184.

60. Tiwari SK, Khan AA, Ibrahim M, Habeeb MA, Habibullah CM. Helicobacter pylori and other Helicobacter species DNA in human bile samples from patients with various hepato-biliary diseases. World J Gastroenterol 2006;12:2181-2186.

61. Bulajic M, Maisonneuve P, Schneider-Brachert W, et al. Helicobacter pylori and the risk of benign and malignant biliary tract disease. Cancer 2002;95:1946-1953.

62. Chang JS, Tsai CR, Chen LT. Medical risk factors associated with cholangiocarcinoma in Taiwan: a population-based case-control study. PLoS One 2013;8:e69981.

63. Pandey M, Shukla M. Helicobacter species are associated with possible increase in risk of hepatobiliary tract cancers. Surg Oncol 2009;18:51-56.

64. Murphy G, Michel A, Taylor PR, et al. Association of seropositivity to Helicobacter species and biliary tract cancer in the ATBC study. Hepatology 2014;60:1963-1971.

65. Kaewpitoon SJ, Loyd RA, Rujirakul R, et al. Helicobacter species are possible risk factors of cholangiocarcinoma. Asian Pac J Cancer Prev 2016;17:37-44.

66. Leelawat K, Suksumek N, Leelawat S, Lek-Uthai U. Detection of VacA gene specific for Helicobactor pylori in hepatocellular carcinoma and cholangiocarcinoma specimens of Thai patients. Southeast Asian J Trop Med Public Health 2007;38:881-885.

67. Sithithaworn P, Yongvanit P, Duenngai K, Kiatsopit N, Pairojkul C. Roles of liver fluke infection as risk factor for cholangiocarcinoma. J Hepatobiliary Pancreat Sci 2014;21:301-308.

68. Xia J, Jiang SC, Peng HJ. Association between liver fluke infection and hepatobiliary pathological changes: a systematic review and meta-analysis. PLoS One 2015;10:e132673.

69. Li J, Han T, Xu L, Luan X. Diabetes mellitus and the risk of cholangiocarcinoma: an updated meta-analysis. Prz Gastroenterol 2015;10:108-117.

70. Shaib YH, El-Serag HB, Davila JA, Morgan R, McGlynn KA. Risk factors of intrahepatic cholangiocarcinoma in the United States: a case-control study. Gastroenterology 2005;128:620-626.

71. Huang YJ, Wu AT, Chiou HY, et al. Interactive role of diabetes mellitus and female sex in the risk of cholangiocarcinoma: a population-based nested case-control study. Oncotarget 2017;8:6642-6651.

72. Carpino G, Puca R, Cardinale V, et al. Peribiliary glands as a niche of extrapancreatic precursors yielding insulin-producing cells in experimental and human diabetes. Stem Cells 2016;34:1332-1342.

73. Chaiteerakij R, Yang JD, Harmsen WS, et al. Risk factors for intrahepatic cholangiocarcinoma: association between metformin use and reduced cancer risk. Hepatology 2013;57:648-655.

74. Ling S, Feng T, Ke Q, et al. Metformin inhibits proliferation and enhances chemosensitivity of intrahepatic cholangiocarcinoma cell lines. Oncol Rep 2014;31:2611-2618.

75. Palmer WC, Patel T. Are common factors involved in the pathogenesis of primary liver cancers? A meta-analysis of risk factors for intrahepatic cholangiocarcinoma. J Hepatol 2012;57:69-76.

76. Expert Panel on Detection, Evaluation, and Treatment of High Blood Cholesterol in Adults. Executive Summary of The Third Report of The National Cholesterol Education Program (NCEP) Expert Panel on Detection, Evaluation, And Treatment of High Blood Cholesterol In Adults (Adult Treatment Panel III). JAMA 2001;285:2486-2497.

77. Shin HR, Lee CU, Park HJ, et al. Hepatitis B and C virus, Clonorchis sinensis for the risk of liver cancer: a case-control study in Pusan, Korea. Int J Epidemiol 1996;25:933-940.

78. Li H, Hu B, Zhou ZQ, Guan J, Zhang ZY, Zhou GW. Hepatitis C virus infection and the risk of intrahepatic cholangiocarcinoma and extrahepatic cholangiocarcinoma: evidence from a systematic review and meta-analysis of 16 case-control studies. World J Surg Oncol 2015;13:161.

79. Plentz RR, Malek NP. Clinical presentation, risk factors and staging systems of cholangiocarcinoma. Best Pract Res Clin Gastroenterol 2015;29:245-252.

80. Zhou HB, Hu JY, Hu HP. Hepatitis B virus infection and intrahepatic cholangiocarcinoma. World J Gastroenterol 2014;20:5721-5729.

81. Zhang H, Zhu B, Zhang H, Liang J, Zeng W. HBV infection status and the risk of cholangiocacinoma in Asia: a meta-analysis. Biomed Res Int 2016;2016:3417976.

82. Cardinale V, Bragazzi MC, Alvaro D. Cholangiocarcinoma epidemiology. In: Brandi $G$ and Ercolani $G$ (editors): Cholangiocarcinoma. Nova Science Publisher Inc.: New York; 2015.

83. Cardinale V, Alvaro D. Molecular Profiling. In: Herman J, Pawlik T, Thomas, CR Jr (editors). Biliary tract and gallbladder cancer: a multidisciplinary approach, $2^{\text {nd }}$ Edition. Springer Science Publishers: New York; 2013.

84. Jiao Y, Pawlik TM, Anders RA, et al. Exome sequencing identifies frequent inactivating mutations in BAP1, ARID1A and PBRM1 in intrahepatic cholangiocarcinomas. Nat Genet 2013;45:1470-1473.

85. Ong CK, Subimerb C, Pairojkul C, et al. Exome sequencing of liver fluke-associated cholangiocarcinoma. Nat Genet 2012;44:690-693.

86. Zou S, Li J, Zhou H, et al. Mutational landscape of intrahepatic cholangiocarcinoma. Nat Commun 2014;5:5696.

87. Borad MJ, Champion MD, Egan JB, et al. Integrated genomic characterization reveals novel, therapeutically relevant drug targets in FGFR and EGFR pathways in sporadic intrahepatic cholangiocarcinoma. PLoS Genet 2014;10:e1004135.

88. Fujimoto A, Furuta M, Shiraishi Y, et al. Whole-genome mutational landscape of liver cancers displaying biliary phenotype reveals hepatitis impact and molecular diversity. Nat Commun 2015;6:6120.

89. Gao Q, Zhao YJ, Wang XY, et al. Activating mutations in PTPN3 promote cholangiocarcinoma cell proliferation and migration and are associated with tumor recurrence in patients. Gastroenterology 2014;146:1397-1407.

90. Boulter L, Guest RV, Kendall TJ, et al. WNT signaling drives cholangiocarcinoma growth and can be pharmacologically inhibited. J Clin Invest 2015;125:1269-1285.

91. Chan-On W, Nairismägi ML, Ong CK, et al. Exome sequencing identifies distinct mutational patterns in liver fluke-related and noninfection-related bile duct cancers. Nat Genet 2013;45:1474-1478.

92. Sia D, Losic B, Moeini A, et al. Massive parallel sequencing uncovers actionable FGFR2-PPHLN1 fusion and ARAF mutations in intrahepatic cholangiocarcinoma. Nat Commun 2015;6:6087. 
93. Nault JC, Zucman-Rossi J. Genetics of hepatobiliary carcinogenesis. Semin Liver Dis 2011;31:173-187.

94. Chen CP, Haas-Kogan D. Neoplasms of the hepatobiliary system: clinical presentation, molecular pathways and diagnostics. Expert Rev Mol Diagn 2010;10:883-895.

95. Kumar M, Zhao X, Wang XW. Molecular carcinogenesis of hepatocellular carcinoma and intrahepatic cholangiocarcinoma: one step closer to personalized medicine? Cell Biosci 2011;1:5.

96. Yoon JH, Higuchi H, Werneburg NW, Kaufmann SH, Gores GJ. Bile acids induce cyclooxygenase- 2 expression via the epidermal growth factor receptor in a human cholangiocarcinoma cell line. Gastroenterology 2002;122:985-993.

97. Yoon JH, Canbay AE, Werneburg NW, Lee SP, Gores GJ. Oxysterols induce cyclooxygenase-2 expression in cholangiocytes: implications for biliary tract carcinogenesis. Hepatology 2004;39:732-738.

98. Jaiswal M, LaRusso NF, Burgart LJ, Gores GJ. Inflammatory cytokines induce DNA damage and inhibit DNA repair in cholangiocarcinoma cells by a nitric oxide-dependent mechanism. Cancer Res 2000;60:184-190.

99. Jaiswal M, LaRusso NF, Shapiro RA, Billiar TR, Gores GJ. Nitric oxide-mediated inhibition of DNA repair potentiates oxidative DNA damage in cholangiocytes. Gastroenterology 2001;120:190-199.

100. Ishimura N, Bronk SF, Gores GJ. Inducible nitric oxide synthase upregulates cyclooxygenase-2 in mouse cholangiocytes promoting cell growth. Am J Physiol Gastrointest Liver Physiol 2004;287:G88-G95.

101. Seol MA, Chu IS, Lee MJ, et al. Genome-wide expression patterns associated with oncogenesis and sarcomatous transdifferentation of cholangiocarcinoma. BMC Cancer 2011;11:78.

102. Jinawath N, Chamgramol Y, Furukawa Y, et al. Comparison of gene expression profiles between Opisthorchis viverrini and non-Opisthorchis viverrini associated human intrahepatic cholangiocarcinoma. Hepatology 2006;44:1025-1038.

103. Wang X, Chen W, Huang Y, et al. The draft genome of the carcinogenic human liver fluke Clonorchis sinensis. Genome Biol 2011;12:R107.

104. Young ND, Campbell BE, Hall RS, et al. Unlocking the transcriptomes of two carcinogenic parasites, Clonorchis sinensis and Opisthorchis viverrini. PLoS Negl Trop Dis 2010;4:e719.

105. Sriraksa R, Zeller C, El-Bahrawy MA, et al. CpG-island methylation study of liver fluke-related cholangiocarcinoma. $\mathrm{Br}$ J Cancer 2011;104:1313-1318.

106. Sakoda LC, Gao YT, Chen BE, et al. Prostaglandin-endoperoxide synthase 2 (PTGS2) gene polymorphisms and risk of biliary tract cancer and gallstones: a population-based study in Shanghai, China. Carcinogenesis 2006;27:1251-1256.

107. Kipp BR, Fritcher EG, Clayton AC, et al. Comparison of KRAS mutation analysis and FISH for detecting pancreatobiliary tract cancer in cytology specimens collected during endoscopic retrograde cholangiopancreatography. J Mol Diagn 2010;12:780-786.

108. Huang L, Frampton G, Liang LJ, Demorrow S. Aberrant DNA methylation profile in cholangiocarcinoma. World J Gastrointest Pathophysiol 2010;1:23-29.

109. Huang L, Frampton G, Rao A, et al. Monoamine oxidase A expression is suppressed in human cholangiocarcinoma via coordinated epigenetic and IL-6-driven events. Lab Invest 2012;92:1451-1460.

110. Melum E, Karlsen TH, Schrumpf E, et al. Cholangiocarcinoma in primary sclerosing cholangitis is associated with NKG2D polymorphisms. Hepatology 2008;47:90-96.

111. Karamitopoulou E, Tornillo L, Zlobec I, et al. Clinical significance of cell cycle- and apoptosis-related markers in biliary tract cancer: a tissue microarray-based approach revealing a distinctive immunophenotype for intrahepatic and extrahepatic cholangiocarcinomas. Am J Clin Pathol 2008;130:780-786.

112. Miller G, Socci ND, Dhall D, et al. Genome wide analysis and clinical correlation of chromosomal and transcriptional mutations in cancers of the biliary tract. J Exp Clin Cancer Res 2009;28:62.

113. Borger DR, Tanabe KK, Fan KC, et al. Frequent mutation of isocitrate dehydrogenase (IDH)1 and IDH2 in cholangiocarcinoma identified through broad-based tumor genotyping. Oncologist 2012;17:72-79.

114. Yang B, House MG, Guo M, Herman JG, Clark DP. Promoter methylation profiles of tumor suppressor genes in intrahepatic and extrahepatic cholangiocarcinoma. Mod Pathol 2005; 18:412-420.

115. Oliveira DV, Zhang S, Chen X, Calvisi DF, Andersen JB. Molecular profiling of intrahepatic cholangiocarcinoma: the search for new therapeutic targets. Expert Rev Gastroenterol Hepatol 2017;11:349-356.

116. Rhee H, Ko JE, Chung $\mathrm{T}$, et al. Transcriptomic and histopathological analysis of cholangiolocellular differentiation trait in intrahepatic cholangiocarcinoma. Liver Int 2017 [Epub ahead of print]. doi: 10.1111/liv.13492.

117. Rizvi S, Gores GJ. Emerging molecular therapeutic targets for cholangiocarcinoma. J Hepatol 2017;67:632-644.

118. Nakanuma Y, Sato Y. Cystic and papillary neoplasm involving peribiliary glands: a biliary counterpart of branch-type intraductal papillary mucinous [corrected] neoplasm? Hepatology 2012;55:2040-2041.

119. Cardinale V, Wang Y, Carpino G, et al. The biliary tree-a reservoir of multipotent stem cells. Nat Rev Gastroenterol Hepatol 2012;9:231-240.

120. Cardinale V, Renzi A, Carpino G, et al. Profiles of cancer stem cell subpopulations in cholangiocarcinomas. Am J Pathol 2015;185:1724-1739.

121. Gandou C, Harada K, Sato Y, et al. Hilar cholangiocarcinoma and pancreatic ductal adenocarcinoma share similar histopathologies, immunophenotypes, and development-related molecules. Hum Pathol 2013;44:811-821.

122. Nakanuma Y, Harada K, Sasaki M, Sato Y. Proposal of a new disease concept "biliary diseases with pancreatic counterparts". Anatomical and pathological bases. Histol Histopathol 2014;29:1-10.

123. Cardinale V, Gatto M, Alvaro D. Clinical features of intrahepatic cholangiocarcinoma. In: Brandi G and Ercolani G (editors). Cholangiocarcinoma. Nova Science Publisher Inc.: New York; 2015.

124. Rimola J, Forner A, Reig M, et al. Cholangiocarcinoma in cirrhosis: absence of contrast washout in delayed phases by magnetic resonance imaging avoids misdiagnosis of hepatocellular carcinoma. Hepatology 2009;50:791-798.

125. Iavarone M, Piscaglia F, Vavassori S, et al. Contrast enhanced CT-scan to diagnose intrahepatic cholangiocarcinoma in patients with cirrhosis. J Hepatol 2013;58:1188-1193.

126. Kim SJ, Lee JM, Han JK, Kim KH, Lee JY, Choi BI. Peripheral mass-forming cholangiocarcinoma in cirrhotic liver. $A J R A m J$ Roentgenol 2007;189:1428-1434.

127. Weber SM, Ribero D, O'Reilly EM, Kokudo N, Miyazaki M, Pawlik TM. Intrahepatic cholangiocarcinoma: expert consensus statement. HPB (Oxford) 2015;17:669-680.

128. Chen J, He J, Deng M, et al. Clinicopathologic, radiologic, and molecular study of 23 combined hepatocellularcholangiocarcinomas with stem cell features, cholangiolocellular type. Hum Pathol 2017;64:118-127.

129. Khan SA, Davidson BR, Goldin RD, et al; British Society of 
Gastroenterology. Guidelines for the diagnosis and treatment of cholangiocarcinoma: an update. Gut 2012;61:1657-1669.

130. Bledsoe JR, Shinagare SA, Deshpande V. Difficult diagnostic problems in pancreatobiliary neoplasia. Arch Pathol Lab Med 2015;139:848-857.

131. European Association for the Study of the Liver. EASL Clinical Practice Guidelines: management of cholestatic liver diseases. $J$ Hepatol 2009;51:237-267.

132. Lindor KD, Kowdley KV, Harrison ME; American College of Gastroenterology. ACG Clinical Guideline: Primary Sclerosing Cholangitis. Am J Gastroenterol 2015;110:646-659; quiz 660.

133. Navaneethan U, Njei B, Lourdusamy V, Konjeti R, Vargo JJ, Parsi MA. Comparative effectiveness of biliary brush cytology and intraductal biopsy for detection of malignant biliary strictures: a systematic review and meta-analysis. Gastrointest Endosc 2015;81:168-176.

134. Rycaj K, Tang DG. Cell-of-origin of cancer versus cancer stem cells: Assays and interpretations. Cancer Res 2015;75:4003-4011.

135. Visvader JE. Cells of origin in cancer. Nature 2011;469:314-322.

136. Cardinale V, Wang Y, Carpino G, Reid LM, Gaudio E, Alvaro D. Mucin-producing cholangiocarcinoma might derive from biliary tree stem/progenitor cells located in peribiliary glands. Hepatology 2012;55:2041-2042.

137. Yamashita T, Wang XW. Cancer stem cells in the development of liver cancer. J Clin Invest 2013;123:1911-1918.

138. Raggi C, Invernizzi P, Andersen JB. Impact of microenvironment and stem-like plasticity in cholangiocarcinoma: molecular networks and biological concepts. J Hepatol 2015;62:198-207.

139. Chen WT, Tseng CC, Pfaffenbach K, et al. Liver-specific knockout of GRP94 in mice disrupts cell adhesion, activates liver progenitor cells, and accelerates liver tumorigenesis. Hepatology 2014;59:947-957.

140. Vander Borght S, Komuta M, Libbrecht L, et al. Expression of multidrug resistance-associated protein 1 in hepatocellular carcinoma is associated with a more aggressive tumour phenotype and may reflect a progenitor cell origin. Liver Int 2008;28:1370-1380.

141. Govaere O, Komuta M, Berkers J, et al. Keratin 19: a key role player in the invasion of human hepatocellular carcinomas. Gut 2014;63:674-685.

142. Magee JA, Piskounova E, Morrison SJ. Cancer stem cells: impact, heterogeneity, and uncertainty. Cancer Cell 2012;21:283-296.

143. Oikawa T. Cancer Stem cells and their cellular origins in primary liver and biliary tract cancers. Hepatology 2016;64:645-651.

144. Leelawat K, Thongtawee T, Narong S, Subwongcharoen S, Treepongkaruna SA. Strong expression of CD133 is associated with increased cholangiocarcinoma progression. World $J$
Gastroenterol 2011;17:1192-1198.

145. Sulpice L, Rayar M, Turlin B, et al. Epithelial cell adhesion molecule is a prognosis marker for intrahepatic cholangiocarcinoma. J Surg Res 2014;192:117-123.

146. Gu MJ, Choi JH. Epithelial-mesenchymal transition phenotypes are associated with patient survival in intrahepatic cholangiocarcinoma. J Clin Pathol 2014;67:229-234.

147. Haraguchi N, Ishii $\mathrm{H}$, Mimori K, et al. CD13 is a therapeutic target in human liver cancer stem cells. J Clin Invest 2010;120:3326-3339.

148. Sukowati CH, Anfuso B, Torre G, Francalanci P, Crocè LS, Tiribelli C. The expression of CD90/Thy-1 in hepatocellular carcinoma: an in vivo and in vitro study. PLoS One 2013;8:e76830.

149. Fabris L, Cadamuro M, Moserle L, et al. Nuclear expression of S100A4 calcium-binding protein increases cholangiocarcinoma invasiveness and metastasization. Hepatology 2011;54:890-899.

150. Julich-Haertel H, Urban SK, Krawczyk M, et al. Cancer-associated circulating large extracellular vesicles in cholangiocarcinoma and hepatocellular carcinoma. J Hepatol 2017;67:282-292.

151. Merino-Azpitarte M, Lozano E, Perugorria MJ, et al. SOX17 regulates cholangiocyte differentiation and acts as a tumor suppressor in cholangiocarcinoma. J Hepatol 2017;67:72-83.

152. Oishi N, Wang XW. Novel therapeutic strategies for targeting liver cancer stem cells. Int J Biol Sci 2011;7:517-535.

153. Reya T, Morrison SJ, Clarke MF, Weissman IL. Stem cells, cancer, and cancer tem cells. Nature 2001;414:105-111.

154. O'Connor ML, Xiang D, Shigdar S, et al. Cancer stem cells: A contentious hypothesis now moving forward. Cancer Lett 2014;344:180-187.

155. Kreso A, Dick JE. Evolution of the cancer stem cell model. Cell Stem Cell 2014;14:275-291.

156. Govaere O, Wouters J, Petz M, et al. Laminin-332 sustains chemoresistance and quiescence as part of the human hepatic cancer stem cell niche. J Hepatol 2016;64:609-617.

157. Raggi C, Correnti M, Sica A, et al. Cholangiocarcinoma stemlike subset shapes tumor-initiating niche by educating associated macrophages. J Hepatol 2017;66:102-115.

158. Fraveto A, Cardinale V, Bragazzi MC, et al. Sensitivity of human intrahepatic cholangiocarcinoma subtypes to chemotherapeutics and molecular targeted agents: a study on primary cell cultures. PLoS One 2015;10:e0142124.

159. Lawson DA, Bhakta NR, Kessenbrock K, et al. Single-cell analysis reveals a stem-cell program in human metastatic breast cancer cells. Nature 2015;526:131-135.

160. Wei M, Lü L, Lin P, Chen Z, Quan Z, Tang Z. Multiple cellular origins and molecular evolution of intrahepatic cholangiocarcinoma. Cancer Lett 2016;379:253-261. 